\title{
Terapia Ocupacional na Unidade de Terapia Intensiva (UTI) adulto e as percepçóes da equipe ${ }^{1}$
}

\author{
Tatiana Barbieri Bombarda ${ }^{a}$, Ana Luiza Lanza ${ }^{b}$, Claudia Aline Valente Santos ${ }^{a}$, \\ Regina Helena Vitale Torkomian Joaquim ${ }^{a}$
}

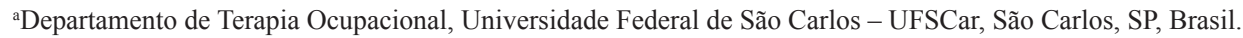

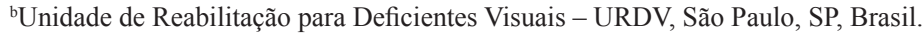

\begin{abstract}
Resumo: Introdução: A Agência Nacional de Vigilância Sanitária (ANVISA), em 24 de fevereiro de 2010, aprovou a resolução de número 7, que dispõe sobre a obrigatoriedade do terapeuta ocupacional como profissional integrante da equipe atuante em Unidade de Terapia Intensiva. Acredita-se que, na terapia ocupacional, o âmbito da UTI se constitui como um local de reduzida atuação profissional, visto o escasso número de publicações encontradas na literatura. Objetivo: Descrever a experiência e as ações desenvolvidas pela terapia ocupacional em uma UTI adulto, bem como relatar a percepção da equipe em relação a esta prática realizada em um Hospital Estadual, localizado no interior do Estado de São Paulo. Método: Trata-se de um relato de experiência em que se realizou análise documental para obtenção de dados referentes às ações desenvolvidas pela terapia ocupacional, assim como a aplicação de um questionário à equipe para compreensão das percepções dos profissionais em relação à assistência prestada. Os dados obtidos foram trabalhados por meio de análise de conteúdo temática. Resultados: Como resultado, foi identificado que as intervenções da terapia ocupacional transitaram por aspectos funcionais e de apoio ao enfrentamento, sendo possível constatar reconhecimento dessas ações pela equipe. Conclusão: A atuação descrita consiste em práticas provenientes do processo de inserção da terapia ocupacional em uma UTI adulto e vai ao encontro do desejo de se estimular o desenvolvimento de pesquisas neste âmbito, para o fomento de debates que promovam aprimoramento técnico da profissão na assistência a pacientes críticos.
\end{abstract}

Palavras-chave: Terapia Ocupacional, Unidade de Terapia Intensiva, Hospitalização.

\section{The Occupational Therapy in adult Intensive Care Unit (ICU) and team perceptions}

\begin{abstract}
Introduction: The National Health Surveillance Agency (ANVISA), on 24 February 2010, adopted resolution number 7, which makes mandatory the presence of an occupational therapist as an active member of the Intensive Care Unit professional team. It is believed that the ICU scope is a small professional practice in Occupational Therapy due to the small number of publications in the literature. Objective: To describe the experience and actions developed by occupational therapy in an adult ICU and report the staff awareness reagrding this practice at a state hospital, located in the state of São Paulo. Method: This is an experience report in which we conducted document analysis to obtain data regarding actions taken by occupational therapy, as well as the application of a questionnaire with the team to understand the professionals perceptions regarding the care provided. The data obtained was processed through thematic content analysis. Results: We identified that the occupational therapy intervention transited by functional aspects and support for coping, with the recognition of these actions by the team. Conclusion: The described action consists of practices derived from the occupational therapy insertion process in an adult ICU and meets the desire to encourage the research development in this area for the promotion of debates to promote technical improvement of the profession in the care of critically ill patients.
\end{abstract}

Keywords: Occupational Therapy, Intensive Care Unit, Hospitalization.

Autor para correspondência: Tatiana Barbieri Bombarda, Universidade Federal de São Carlos, Rodovia Washington Luis, Km 235, CEP 13565-905, São Carlos, SP, Brasil, e-mail: tatibb_to@yahoo.com.br

Recebido em Maio 17, 2016; $1^{\text {a }}$ Revisão em Ago. 1, 2016; $2^{\text {a }}$ Revisão em Set. 26, 2016; Aceito em Out. 3 , 2016. 


\section{Introdução}

A Unidade de Terapia Intensiva (UTI) se caracteriza como um serviço de açóes imediatas e priorização de atividades técnicas, envolvendo complexidade tecnológica, gravidade da doença e profissionais especializados (MACIEL; SOUZA, 2006). Em decorrência desta constituição, a UTI parece oferecer um dos ambientes mais tensos, agressivos e traumatizantes do âmbito hospitalar (PROENÇA; AGNOLO, 2011), também sendo vista como um espaço relacionado ao sofrimento e à morte (GUIRARDELLO et al., 1999).

O paciente de cuidado intensivo é caracterizado como o indivíduo que apresenta um quadro grave e recuperável, requerendo assistência clínica permanente e especializada, visto o risco iminente de morte e instabilidade de funçôes vitais (CONSELHO..., 2012), fator que denota a necessidade do atendimento na unidade de tratamento intensivo ser ofertado por uma equipe multiprofissional especializada. Os profissionais atuantes nesta unidade devem ter preparo para a lida de instabilidades do quadro clínico, assim como devem apresentar conhecimentos teóricos relacionados à área específica da terapia intensiva (PAIVA et al., 2002).

Em relação à Terapia Ocupacional, a atuação pode envolver açôes de prevenção, promoção, proteção, educação, intervenção e reabilitação do paciente, a fim de se prevenirem deformidades, disfunçóes e agravos físicos e/ou psicossociais e afetivos, e de modo a promover o desempenho ocupacional e a qualidade de vida do indivíduo (CONSELHO..., 2012).

Para Galheigo (2007), a incorporação do terapeuta ocupacional como profissional essencial na equipe de saúde do hospital é uma concepção ainda não consolidada. Todavia, é importante ressaltar os avanços obtidos na área hospitalar, considerando-se a aprovação da especialidade dos terapeutas ocupacionais em Contextos Hospitalares (CONSELHO..., 2013), bem como a aprovaçáo pela Agência Nacional de Vigilância Sanitária - ANVISA, em 24 de fevereiro de 2010, da Resolução no 7, a qual dispóe acerca dos recursos assistenciais para funcionamento da UTI, incluindo o Terapeuta Ocupacional como profissional obrigatório na composição da equipe multiprofissional (AGÊNCIA..., 2010).

Não obstante, em 2012, foram estabelecidos os Parâmetros Assistenciais para as diversas modalidades prestadas pelo terapeuta ocupacional, sendo sinalizada, para atuação nas unidades de terapia intensiva, seja esta pediátrica ou adulta, a estimativa de oito atendimentos por turno de seis horas de trabalho, sendo estipulados 45 minutos a duraçáo de cada consulta (CONSELHO..., 2012).

Apesar de acreditar que o terapeuta ocupacional possui habilidades e técnicas que auxiliam favoravelmente no tratamento do paciente crítico, cientificamente, escassos estudos foram encontrados com esta temática no Brasil e no cenário internacional.

Entre as publicaçôes encontradas com enfoque na população adulta, pode-se apontar o artigo "Terapia Ocupacional y Paciente Crítico", que expressa dados de uma pesquisa de caráter exploratório relativa a um levantamento de características dos pacientes críticos de uma unidade intensiva de um hospital chileno e possibilidades de abordagem do terapeuta ocupacional, sendo avaliada a pertinência da implementação de um programa de Terapia Ocupacional neste local (CELIS et al., 2014).

Como perfil da amostra do estudo supracitado, foram referenciadas características, como alta presença de edemas em mãos; diminuição de amplitude articular de mãos e dedos; alta frequência de uso de ventilação mecânica; estar sujeito à sedação; comprometimentos no nível de consciência; exposição a estímulos do ambiente intra-hospitalar, e carência de estímulos que evoquem a realidade externa. Os autores apontam que, a partir do contexto e das características apresentadas, a intervenção da Terapia Ocupacional se constitui como um aporte ao tratamento, visto que possui bases teórico-práticas que auxiliam na prevenção de grande parte dos déficits apresentados, em especial através de intervenção precoce, assumindo, o terapeuta ocupacional, papel náo desenvolvido por outros profissionais da equipe. Além disso, é ressaltada a importância de, nos tempos atuais, assistir o sujeito considerando-se todas suas dimensôes e seu contexto, partindo do pressuposto da integralidade do cuidado (CELIS et al., 2014).

Em outro estudo publicado, Dinglas et al. (2013) avaliaram a associação entre pacientes, UTI e fatores hospitalares com a temporalidade para a primeira intervençấo da terapia ocupacional de pacientes com lesão pulmonar aguda, constatando que apenas $30 \%$ destes pacientes receberam intervenção da terapia ocupacional durante estadia na UTI. Piora na função orgânica, hemodiálise contínua e infusão ininterrupta de sedação foram variáveis associadas ao adiamento do início da assistência de terapia ocupacional.

Outra importante publicação a ser destacada consiste em uma pesquisa de Alvarez et al. (2012), que apresentam um estudo clínico randomizado, comparando a efetividade do tratamento não farmacológico padrão com o tratamento não farmacológico reforçado (assistência padrão e terapia 
ocupacional) na incidência de delirium em idosos hospitalizados em uma unidade de terapia intensiva do Chile. Os sujeitos participantes foram 70 pacientes idosos, divididos em um grupo controle, que recebeu assistência padrão, e um grupo que recebeu assistência padronizada em conjunto com assistência de terapia ocupacional. Como resultados, foi possível verificar que o grupo que recebeu assistência com intervençôes da terapia ocupacional apresentou menor incidência de delirium, menos tempo de internação e melhor nível de independência funcional motora na alta (ALVAREZ et al., 2012), fatores que demonstram indicadores expressivos da relevância do trabalho da terapia ocupacional e da necessidade de este profissional estar inserido na composição da equipe multiprofissional da UTI.

Segundo Santos e De Carlo (2013), os estudos demonstram que a atuaçáo do terapeuta ocupacional junto a pacientes hospitalizados proporciona melhor enfrentamento da condição de internação, melhores níveis de independência, funcionalidade e qualidade de vida, bem como pode facilitar a retomada da vida cotidiana e a participaçáo social dos indivíduos. A intervenção terapêutica ocupacional é apontada como promotora do resgate da vida cotidiana impactada pelo adoecimento e pela situação de hospitalização.

Deste modo, acredita-se que a terapia ocupacional pode contribuir, de forma efetiva, na assistência prestada no âmbito da UTI adulto; porém, visualiza-se a necessidade de desenvolvimento de conhecimento técnico-científico nesta temática para fomentar debates, trocas de experiências e disseminação das especificidades da atuação profissional, visto reduzidas publicaçóes existentes.

Diante deste contexto, com a proposta de partilhar a experiência dos primeiros nove meses do trabalho de terapia ocupacional na UTI, este artigo visou a descrever a experiência e as açóes práticas desenvolvidas pelo setor, e relatar a percepção da equipe assistencial da UTI em relação ao trabalho desempenhado pelo Terapeuta Ocupacional.

\section{Método}

Trata-se de um relato de experiência pautado na vivência do setor de terapia ocupacional no âmbito da UTI de um hospital estadual de nível secundário, de média complexidade, localizado no interior do Estado de São Paulo.

O setor de terapia ocupacional neste hospital é composto por quatro profissionais, os quais se distribuem como referências por sete enfermarias: clínica geral, cirúrgica, moléstias infecciosas, cuidados paliativos, unidade semi-intensiva e intensiva. No caso da UTI, é importante destacar que o terapeuta ocupacional de referência não fica em tempo integral na unidade, se deslocando para clínica intensiva mediante pedidos de interconsulta, assim como, semanalmente, para participação em reuniấo de equipe.

Metodologicamente, foi realizada análise documental de prontuários e formulários específicos do setor referente às anotaçôes do período dos nove meses iniciais de atuação da terapia ocupacional na UTI, com vista de possibilitar a amostragem referente às açôes do serviço de terapia ocupacional prestado.

Em complemento, ao final do nono mês de inserçáo da terapia ocupacional na UTI, o profissional realizou aplicação de um questionário à equipe, com consentimento institucional, para compreensão das percepçôes dos profissionais em relação à assistência prestada visando, a posteriori, investimentos em açóes educativas com a equipe assistencial sobre a prática da terapia ocupacional. Foram sujeitos, desta etapa, dois médicos, dois psicólogos, um nutricionista, um fisioterapeuta, um enfermeiro, um assistente social e um fonoaudiólogo. A aplicação do questionário se deu in loco, após reunião multiprofissional, sendo explicitado o caráter de participação voluntária e tendo todos assinado o Termo de Consentimento Livre e Esclarecido.

O questionário foi composto por três questôes que buscaram compreender aspectos correlacionados às vivências prévias dos profissionais com terapeutas ocupacionais, ao entendimento das açôes praticadas e à visualizaçáo de possíveis contribuiçóes do terapeuta ocupacional na UTI pela ótica da equipe.

Os dados obtidos referentes às intervençôes realizadas e às percepçóes dos profissionais foram analisados tematicamente. A análise de conteúdo temático consiste em uma técnica em que se realiza leitura flutuante, até esgotar a totalidade das informações registradas para verificação da repetição de temas, fator que propicia organização dos dados em categorias e interpretação destas com base em referenciais teóricos (MINAYO, 2007).

\section{Resultados e Discussão}

\subsection{Inserção da Terapia Ocupacional na UTI}

A inserção do terapeuta ocupacional na unidade de terapia intensiva adulto de um hospital geral ocorreu inicialmente por meio das participaçóes semanais nas reunióes multiprofissionais voltadas às discussóes de casos clínicos. Tal participação 
permitiu a utilização deste espaço de trocas para, além das contribuições no tratamento, explanar às outras especialidades as possibilidades interventivas e competências do terapeuta ocupacional.

Durante esses nove meses de atuação, verificou-se que a assistência realizada envolveu pacientes com média de idade de 54 anos (sendo a idade mínima atendida de 16 e a máxima, de 84 anos) e com igual representação no gênero ( $50 \%$ do sexo masculino e $50 \%$ feminino). Considerando-se apenas o diagnóstico primário, os quadros clínicos mais frequentes corresponderam a comprometimentos respiratórios $(50,95 \%)$, renais $(20,75 \%)$ e cardíacos $(11,32 \%)$.

Destaca-se que, ao longo dos três primeiros meses de prática nesta unidade, ocorreram reduzidos pedidos de interconsulta $(n=4)$, fator que pode estar associado à pouca apropriação da equipe em relação às intervençôes desenvolvidas pelo terapeuta ocupacional. Para tanto, neste período, os atendimentos realizados foram provenientes $\mathrm{da}$ busca ativa do terapeuta ocupacional ou a partir de demandas visualizadas nas discussões clínicas.

Segundo Carvalho e Lustosa (2008), a interconsulta pode ser considerada como um modo de aplicaçáo do conceito de interdisciplinaridade, o que vai ao encontro da definiçáo de Schmitt e Gomes (2005) da interconsulta como uma atividade interprofissional e interdisciplinar.

Verificou-se que, a partir dos atendimentos realizados no primeiro trimestre e das trocas desenvolvidas com a equipe acerca das açóes interventivas realizadas neste período, houve um aumento de solicitaçōes para avaliação pela terapia ocupacional, o que culminou, no período dos seis meses posteriores, na realização de 20 pedidos de interconsulta. Trata-se de uma média assistencial de três avaliaçôes de pacientes ao mês, em uma unidade com dez leitos, desdobrando-se em 129 atendimentos no semestre.

\subsection{Práticas da Terapia Ocupacional}

O processo de avaliação do terapeuta ocupacional pautava-se em um roteiro avaliativo do setor, no qual constavam: a coleta de informaçôes sobre a estruturação familiar do paciente, o perfil ocupacional, o perfil de compreensão e aceitação da doença, a queixa principal e a aplicação da escala de Katz ${ }^{2}$.

$\mathrm{Na}$ identificação das açôes prestadas pelo terapeuta ocupacional, as intervençôes registradas foram categorizadas em: acolhimento, enfrentamento, comunicação, funcionalidade e família, conforme descrito no Tabela 1.

A categoria acolhimento consistiu nas açôes registradas referentes à escuta ativa efetivada frente à instabilidade emocional de pacientes e também de familiares, ação que permitiu entendimento da configuraçáo de anseios e problemáticas delineadas pelo usuário e seus acompanhantes, concepçóes estas que, por vezes, foram percebidas como aspectos influentes na exacerbação de sintomas. O acolhimento, uma diretriz da Política Nacional de Humanização - PNH, refere-se à atitude profissional em acolher as diferenças, as dores, os modos de viver e sentir a vida. Consiste na realização de escuta qualificada e na capacidade de pactuação entre as demandas avaliadas e a possibilidade de resposta do serviço (BRASIL, 2010).

Em outra categoria denominada enfrentamento, foram agrupadas açóes realizadas pelo terapeuta ocupacional em decorrência de dificuldades relacionadas à internação, à negligência ao tratamento e à aceitação das limitaçôes temporárias ou permanentes. Para Botega (2002), a enfermidade ocasiona, no paciente, o sentimento de perda do controle sobre si, sendo as reaçóes vivenciadas por cada indivíduo, frente ao adoecimento e à hospitalização, manifestadas de modo diferente. As intervençôes atreladas à categoria enfrentamento consistiram em orientaçôes gerais (esclarecimentos sobre quadro clínico e prognóstico funcional, minimização de dúvidas e desconstrução de fantasias); proposições reflexivas (identificação de fatores e horários de maior intensidade de sintomas para estratégias de manejo, incorporação de corresponsabilidade e estímulos a posturas assertivas); visualização do uso de atividades de interesse como recurso de minimização de queixas, bem como da apresentação

Tabela 1. Ações empregadas pelo Terapeuta Ocupacional no âmbito da UTI adulto.

\begin{tabular}{|c|c|}
\hline CATEGORIAS & AÇÕES DESENVOLVIDAS \\
\hline Acolhimento & Escuta ativa, pactuação \\
\hline Enfrentamento & Orientações, Reflexões, Atividades de interesse \\
\hline Comunicação & Pranchas de comunicação alternativa, adaptação de escrita, treinamento de sinais corporais \\
\hline Funcionalidade & $\begin{array}{l}\text { Atividades expressivas, artesanais, jogos adaptados, AVDs, mobilizações, } \\
\text { posicionamento }\end{array}$ \\
\hline Família & $\begin{array}{l}\text { Acolhimento, mediação de conflitos, atividades expressivas, estratégias para } \\
\text { organização de rotina e suporte ao luto }\end{array}$ \\
\hline
\end{tabular}


de serviços disponíveis na rede enquanto suporte para o pós-alta (encorajamento e estruturação para investimento no autocuidado).

Em comunicação, foram englobadas açôes vinculadas às dificuldades de expressão dos pacientes, fator assistido por meio do uso de prancha de comunicação alternativa, bem como pela utilização de recursos alternativos, como escrita adaptada e sinais corporais ou faciais.

Kleinpell et al. (2009) manifestam que muitos dos pacientes de unidades intensivas apresentam expressóes por gestos e movimentaçóes labiais no intuito de se comunicarem, mas que, pela subjetividade presente nestas tentativas, por vezes, há interpretações equivocadas pelos profissionais, gerando frustração e angústias ao paciente. Neste sentido, a empregabilidade de recursos de comunicação alternativa, de baixa complexidade, em especial nos centros intensivos, tendem a favorecer uma interação eficaz desde que haja entendimento e aplicabilidade sistemática por todos membros da equipe (BEUKELMAN; MIRENDA, 1992).

De acordo com Luzo, Mello e Capanema (2004), falta treinamento específico para que os profissionais se tornem provedores de tecnologia assistiva. Neste contexto, na prática vivenciada, foi possível perceber que a efetividade dos recursos de comunicaçáo alternativa náo consistia apenas na elaboração e na intervenção de terapia ocupacional, mas também na instrumentalização ofertada pelo terapeuta ocupacional à equipe em como utilizar os recursos prescritos, o que envolve posicionamento, simplificação de perguntas, respeito a tempo de resposta, entre outros.

A empregabilidade de atividades expressivas, artesanais e uso de jogos adaptados, bem como a abordagem das atividades de vida diária (AVDs), também foi utilizada pelo terapeuta ocupacional, dando origem à categoria funcionalidade. Nos registros analisados, consta que, de início, na realização destas, o terapeuta ocupacional efetivava mobilizaçóes articulares, posicionamento e, quando necessário, adaptaçôes para favorecer desempenho funcional, intervençôes que vão ao encontro da descrição da atuação em nível hospitalar, conforme referido por Carvalho (2004). É importante relatar que a escolha de atividades manuais e de jogos ocorreu pautada por informaçóes do contexto de vida do paciente e dos seus interesses. Além disso, houve registro, no prontuário, da sinalizaçáo da percepção de pacientes quanto ao emprego das atividades ocasionarem também efeito de facilitação para regulação emocional.
Há de se considerar que, no âmbito da UTI, estão usuários com acometimentos graves, em que fatores, como ventilação mecânica, sedação, traqueostomia, úlceras por pressão, edemas, desorientaçáo e baixo nível de consciência, podem vir a dificultar as intervençóes, gerando muitas vezes sentimentos de angústia e impotência aos profissionais, inclusive terapeutas ocupacionais. Para tanto, é necessário se considerarem todos os fatores deste entorno e compreender o percurso da doença e suas implicaçóes.

A partir da apropriaçáo da rotina da UTI, do entendimento de seus equipamentos, o terapeuta ocupacional desenvolve maior segurança prática, identificando estratégias para aplicação de seus recursos técnicos em meio à instabilidade das condiçóes clínicas nos quadros críticos.

Entende-se, como relevante, refletir que, quando pensamos no ambiente da UTI, fatores, como ruídos dos equipamentos, nível de stress proporcionado e necessidade de práticas invasivas, levam a uma caracterização de um local frio, ríspido, o que não favorece estímulos principalmente concernentes ao acolhimento. Para tanto, a proposta de humanização preconizada pelo SUS deve abranger e se estabelecer também neste âmbito.

Para considerar um hospital como humanizado, tornam-se necessários investimentos voltados à estrutura física, tecnológica, humana e administrativa, em que se valoriza e se respeita o indivíduo colocando-se a serviço dele, garantindo-lhe um atendimento de elevada qualidade (MEZZOMO, 2001).

A compreensão de atendimento qualificado deve envolver critérios, como a composição de uma equipe multiprofissional, a estruturação física adequada e a disponibilidade de tecnologias para usufruto.

Passos et al. (2015) relatam que um dos grandes desafios da equipe de saúde é o de aliar os recursos tecnológicos da UTI aos valores humanitários, visto que a rotina envolve interação constante com a tecnicidade do cuidado, fator essencial para a assistência aos quadros críticos.

Tais fatores são percebidos como benéficos na prática deste hospital, visto esta instituição propiciar horários ampliados de visitas para os familiares e contar com atuação de equipe multiprofissional, televisores em cada quarto, prontuários eletrônicos, além de o espaço físico da UTI ser constituído por dez quartos individualizados, em que metade destes possui vista para a área externa do hospital.

Os recursos supracitados são percebidos enquanto facilitadores no processo assistencial, tendo em vista contribuir para um acolhimento mais adequado 
ao paciente, diminuindo, por vezes, parte dos desgastes emocionais por permitir acompanhamento de familiares em amplo tempo, estimular noção de temporalidade considerando vista externa em metade dos leitos e privacidade por conta de os quartos serem individualizados, fator que facilita a abordagem acerca de sofrimentos existentes e minimiza estímulos externos que dificultam nível de atenção do paciente durante a intervençáo.

Tal abertura à família em permanecer por um tempo maior dentro do ambiente da UTI pode acarretar em ambivalência de sentimentos, visto haver relatos de segurança, por estar presente e demonstrar-se solícito, mas também de expressóes como de impotência e anseios pelo pouco entendimento dos equipamentos de monitoração, e percepçóes das limitaçóes do paciente.

Nesta vertente, emerge a categoria família, a qual consiste em intervençóes realizadas com as figuras de suporte da rede social do paciente. A partir da identificação singular de cada modo de reação adotado pelos acompanhantes, trabalharam-se orientaçôes correlacionadas a facilitaçáo da comunicação com o paciente; auxílio na organização da dinâmica familiar, visto desestruturaçáo diante do adoecimento de um ente, bem como acolhimento frente à expressão de sentimentos e expectativas voltadas ao prognóstico, o que envolve manifestaçóes de luto antecipatório.

De acordo com Pettengill e Angelo (2005), os familiares de pacientes hospitalizados em UTI tendem a apresentar postura defensiva e dificuldades de relacionamento com a equipe de saúde, podendo adotar distanciamentos, fatores vinculados a vivência e experimentação de sentimentos, como impotência e insegurança frente ao desconhecido, o que reforça a necessidade de intervençôes com a família.

Diante deste contexto, verificou-se que os recursos interventivos utilizados pelo terapeuta ocupacional variaram entre treinamentos de tecnologia assistiva para interação do familiar com o paciente; oferta de espaço de escuta qualificada para acolhimento; mediação de conflitos; atividades focadas na expressividade para suporte às emoçóes emergidas pela hospitalização e em ações reflexivas para (re) organização de papéis desempenhados, e identificação de figuras de apoio e de recursos potencializadores ao enfrentamento. Houve também a participação em alguns informes de óbito realizados pelo médico aos familiares, para prestação de auxílio no suporte das manifestaçóes provenientes do luto, tendo em vista o vínculo terapêutico instituído.

\subsection{Percepção da equipe multiprofissional sobre a Terapia Ocupacional}

Com relação à equipe multiprofissional, o terapeuta ocupacional participa semanalmente das discussões de caso clínico, contribuindo com sua visão holística para elaboração de condutas que envolvam minimização de sofrimento e auxílio aos profissionais na identificação de mecanismos assistenciais que possam favorecer o desempenho dos cuidados ofertados.

Através de um breve questionário aplicado a dois médicos, dois psicólogos, um nutricionista, um fisioterapeuta, um enfermeiro, um assistente social e um fonoaudiólogo, buscou-se verificar a percepção da equipe multiprofissional acerca do trabalho da terapia ocupacional neste âmbito.

Perceberam-se, pela ótica dos profissionais, aproximação com o trabalho iniciado e reconhecimento por parte da equipe, frente às açóes desenvolvidas pelo terapeuta ocupacional. Salienta-se que $88,9 \%$ $(\mathrm{n}=8)$ dos profissionais respondentes afirmaram que tiveram contato com o trabalho da terapia ocupacional no âmbito da UTI pela primeira vez, nesta instituição.

As respostas foram trabalhadas por meio da análise de conteúdo temática, sendo descritas pelos participantes ações terapêuticas que vão ao encontro do trabalho desempenhado, conforme ilustrado na Figura 1.

$\mathrm{Na}$ Figura 1, estão explicitadas as categorias elencadas a partir da análise das respostas dadas pela equipe e que denotam a percepção em relação à atuação da terapia ocupacional. Dentre as açóes mais citadas, estáo o auxílio ao enfrentamento e o uso de atividades relacionadas à possibilidade do fazer e, como consequência, o favorecimento de uma postura positiva e de maior engajamento do paciente ao tratamento. Também foram citadas ações de reabilitação e de abordagem nas atividades de vida diária - AVDs, relacionadas ao estímulo à funcionalidade e à independência, atreladas muitas vezes à confecção de adaptações e ao uso de comunicação alternativa. A ressignificação da vida foi manifestada pela percepção da equipe de que os recursos empregados promovem o despertar de novos significados na frágil vivência da hospitalização e frente à sensação da falta de domínio do paciente sobre si mesmo. O auxílio à equipe foi relatado por colocações, como: a terapia ocupacional agrega subsídios à qualidade da assistência e favorece um atendimento mais humanizado, assim como ajuda 


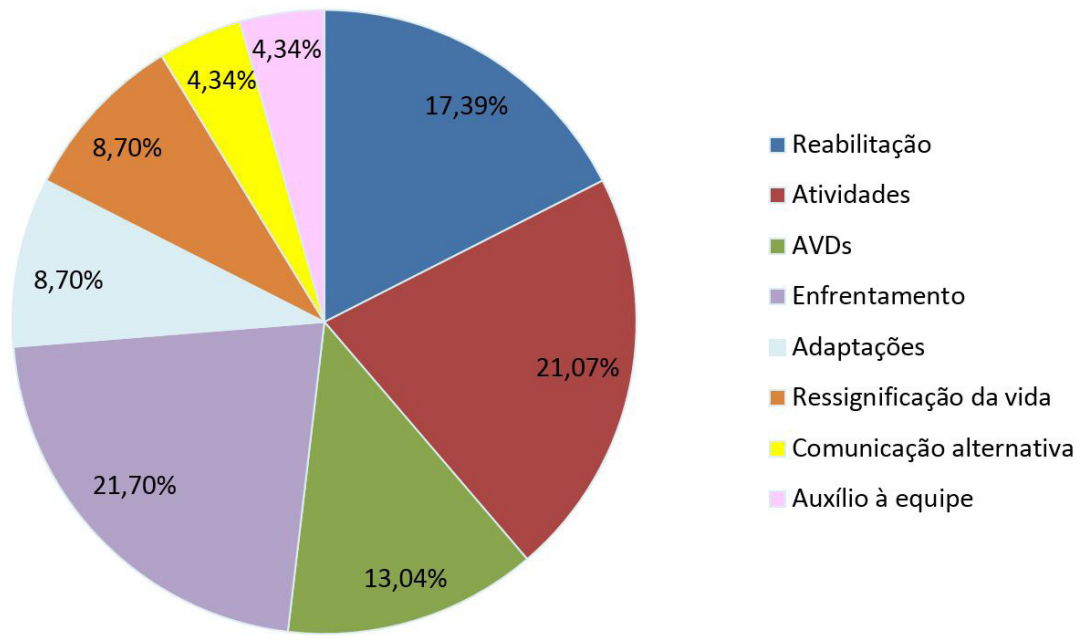

Figura 1. Ações visualizadas pela equipe mediante trabalho da T.O.

a equipe na prestação dos cuidados ao paciente, visto a utilizaçáo de uma pluralidade de recursos terapêuticos.

Em específico, nas atividades de vida diária (AVDs), foram expressas pelos profissionais açōes da terapia ocupacional voltadas a estímulos funcionais nas atividades, como banho, vestuário e alimentação, fator interligado, por vezes, à elaboração de adaptaçôes. A reabilitaçâo foi apontada mediante visualizações de mobilizaçốes e posicionamentos.

$\mathrm{O}$ uso da realização de atividades foi percebido como favorecedor ao enfrentamento da hospitalização e da recuperação funcional, visto que a possibilidade do fazer remete à equipe e aos familiares a melhora funcional e clínica do paciente, minimizando sentimentos desfavoráveis.

A comunicação alternativa foi relatada, sendo percebida vinculada ao uso e ao treinamento de pranchas desenvolvidas pelo setor de terapia ocupacional em conjunto com a fonoaudiologia, para facilitar a interaçáo com o paciente, assim como foi referido o reconhecimento do emprego de outros recursos, como engrossadores, e as orientaçôes sobre temporalidade, para se obterem respostas. Percebeu-se, também, o recurso acerca de posicionamento, de modo a favorecer o campo visual do paciente para leitura labial, para facilitar movimentos de escrita ou gesticulaçôes.

$\mathrm{Na}$ categoria enfrentamento, foi trazido pela equipe que intervençóes de terapia ocupacional auxiliam os pacientes em percepçóes positivas, visto visualização de recursos de apoio e estímulos ao desenvolvimento destas. Alguns profissionais referenciaram, considerando a trajetória clínica e a vivência na UTI, percepções de (res)significação ao longo das intervenções manifestadas pelos pacientes.

Tais sinalizaçóes demonstraram que, no decorrer do contato com a prática da terapia ocupacional, ao longo dos noves meses iniciais da inserção da terapia ocupacional na UTI deste hospital, a equipe manifestou compreensão das possibilidades interventivas, afirmação esta possível de ser feita a partir da associação das percepçôes relatadas pelos profissionais da equipe ser condizentes às açôes efetivadas e registradas pelo terapeuta ocupacional.

A obtenção de percepçóes da equipe de modo condizente ao trabalho efetivado parte do pressuposto de uma prática interdisciplinar, perspectiva esta que, segundo Matos e Pires (2009), permite compreender melhor a multidimensionalidade do objeto de trabalho em saúde, obtendo-se resultados mais satisfatórios.

Para tanto, o terapeuta ocupacional configura-se como um apoiador matricial, ou seja, um especialista que apresenta um núcleo de conhecimento que agrega recursos de saber e contribui com intervençóes que aumentam a capacidade de resolver problemas de saúde da equipe de referência responsável pelo caso (CAMPOS; DOMITTI, 2007).

Nesta perspectiva, a trajetória da terapia ocupacional em contextos hospitalares, no cenário brasileiro, apresenta avanços e desafios, tanto no que tange ao desenvolvimento da prática profissional como à produção técnico-científica e à organização de associaçôes (PALM, 2016). 


\section{Conclusão}

Apesar de a atuação da Terapia Ocupacional no âmbito da UTI adulto não ser ainda difundida, este relato de experiência traz apontamentos acerca de algumas açôes que vêm sendo desenvolvidas na unidade deste relato, com a percepção de reconhecimento das mesmas por outros integrantes da equipe assistencial.

Verificou-se que as açóes empregadas neste hospital transitaram por aspectos funcionais e de apoio ao enfrentamento, sendo o uso de recursos utilizados diversificado, o que demonstra a amplitude do repertório da Terapia Ocupacional.

Todavia, na vivência assistencial, perceberam-se dificuldades atreladas à disseminação do conhecimento acerca da terapia ocupacional entre as especialidades, fator que exigiu esforços conjuntos para a maior inserção nas discussões clínicas e o desenvolvimento de ações educativas, ponderando as limitaçóes vinculadas a recursos humanos (número de terapeutas ocupacionais $\times$ número de enfermarias).

Acredita-se que, em menos de um ano, alcançaram-se espaços importantes de atuação neste hospital, como a atuação na unidade de tratamento intensivo, sendo as barreiras presentes vinculadas à falta de apropriaçáo da equipe acerca da terapia ocupacional, fator que gradativamente diluiu-se com as trocas de conhecimento propostas. Contudo, este é um caminho árduo, considerando-se a rotatividade de profissionais no contexto hospitalar.

A proposta de compartilhar as açóes do trabalho de terapia ocupacional realizado neste hospital vai ao encontro do desejo de se estimular o desenvolvimento de pesquisas no contexto da UTI para visualização do que se tem desenvolvido, assim como para o fomento de debates que promovam aprimoramento técnico e consolidação da atuação do terapeuta ocupacional neste âmbito.

\section{Referências}

AGÊNCIA NACIONAL DE VIGILÂNCIA SANITÁRIA - ANVISA. Resolução no 7, de 24 de fevereiro de 2010. Dispõe sobre os requisitos mínimos para funcionamento de Unidades de Terapia Intensiva e dá outras providências. Diário Oficial da Uniäo, Poder Executivo, Brasília, DF, 25 fev. 2010. Disponível em: <http://bvsms.saude.gov.br/bvs/saudelegis/anvisa/2010/ res0007_24_02_2010.html . Acesso em: 3 set. 2012.

ALVAREZ, E. et al. Terapia ocupacional precoz e intensiva enlaprevencióndel delirium en adultos mayoresingresados a unidades de paciente crítico. ensayo clínico randomizado: resultados preliminares. Revista Chilena de Terapia Ocupacional, Chile, v. 12, n. 1, p. 44-59, 2012. Disponível em: <http://www.revistaterapiaocupacional.
uchile.cl/index.php/RTO/article/view/22051/23368>. Acesso em: 27 mar. 2016.

BEUKELMAN, D. R.; MIRENDA, P. Augmentative and alternative communication: management of severe communication disorders in children and adults. Baltimore: Paul H. Brookes, 1992.

BOTEGA, N. J. Reação à doença e à Hospitalização. In: BOTEGA, N. J. Prática Psiquiátrica no Hospital Geral: interconsulta e emergência. Porto Alegre: Artmed, 2002. p. 43-59.

BRASIL. Ministério da Saúde. Secretaria de Atençáo à Saúde. Núcleo Técnico da Política Nacional de Humanizaçáo. Acolhimento nas práticas de produção de saúde. Brasília: Editora do Ministério da Saúde, 2010.

CAMPOS, G. W. S.; DOMITTI, A. C. Apoio matricial e equipe de referência: uma metodologia para gestão do trabalho interdisciplinar em saúde. Cadernos de Saúde Pública, Rio de Janeiro, v. 23, n. 2, p. 399-407, 2007.

CARVALHO, L. M. G. Terapia Ocupacional na reabilitação de pacientes neurológicos adultos. In: DE CARLO, M. M. R. P.; LUZO, M. C. M. Terapia Ocupacional: reabilitação física e contexto hospitalares. São Paulo: Roca, 2004. p. 201-232.

CARVALHO, M. R.; LUSTOSA, M. A. Interconsulta psicológica. Revista SBPH, Rio de Janeiro, v. 11, n. 1, p. 31-47, 2008.

CELIS, F. et al. Terapia ocupacional y paciente crítico. Revista Chilena de Terapia Ocupacional, Chile, v. 14, n. 1, p. 101-110, 2014.

CONSELHO FEDERAL DE FISIOTERAPIA E TERAPIA OCUPACIONAL - COFFITO. Resolução n ${ }^{\circ}$ 418, de 4 de junho de 2012. Fixa e estabelece os parâmetros assistenciais Terapêuticos Ocupacionais nas diversas modalidades prestadas pelo terapeuta ocupacional e dá outras providências. Diário Oficial da União, Poder Executivo, Brasília, DF, 6 jun. 2012. Disponível em: $<$ https://www.legisweb.com.br/legislacao/?id=243890 $>$. Acesso em: 18 ago. 2016.

CONSELHO FEDERAL DE FISIOTERAPIA E TERAPIA OCUPACIONAL - COFFITO. Resolução no 429, de 08 de julho de 2013. Reconhece e disciplina a especialidade de Terapia Ocupacional em Contextos Hospitalares, define as áreas de atuaçáo e as competências do terapeuta ocupacional especialista em Contextos Hospitalares e dá outras providências. Diário Oficial da Uniāo, Poder Executivo, Brasília, DF, 2013. Disponível em: <http://www.normaslegais.com.br/legislacao/resolucao-coffito-429-2013.htm>. Acesso em: 18 ago. 2016.

DINGLAS, V. D. et al. Occupational Therapy for patients with acute lung injury: factors associate with time to first intervention in the intensive care unit. American Journal Occupational Therapy, Boston, v. 67, n. 3, p.355362, 2013.

GALHEIGO, S. M. Domínios e temáticas no campo das práticas hospitalares em terapia ocupacional: uma 
revisão da literatura brasileira de 1990 a 2006. Revista da Escola de Enfermagem da USP, São Paulo, v. 18, n. 3, p. 113-121, 2007.

GUIRARDELLO, E. B. et al. A percepção do paciente sobre sua permanência na Unidade de Terapia Intensiva. Revista da Escola de Enfermagem da USP, São Paulo, v. 33, n. 2, p. 123-129, 1999. http://dx.doi.org/10.1590/ S0080-62341999000200003.

KLEINPELL, R. M. et al. Improving Communication in the ICU. Advance for Respiratory Care \& Sleep Medicine, Prussia, 13 jul. 2009. Disponível em: <https://respiratory-care-sleep-medicine.advanceweb.com/article/ improving-communication-in-the-icu-6.aspx $>$. Acesso em: 26 ago. 2015.

LINO, V. T. S. et al. Adaptação transcultural da escala de independência em atividades da vida diária (Escala Katz). Cadernos de Saúde Pública, Rio de Janeiro, v. 24, n. 1, p. 103-112, 2008.

LUZO, M. C. M.; MELLO, M. A. F.; CAPANEMA, V. M. Recursos tecnológicos em Terapia Ocupacional: órteses e tecnologia assistiva. In: DE CARLO, M. M. R. P.; LUZO, M. C. M. Terapia Ocupacional: reabilitação física e contexto hospitalares. São Paulo: Roca, 2004. p. 99-126.

MACIEL, M.; SOUZA, M. F. Acompanhante de adulto na Unidade de Terapia Intensiva: uma visão do paciente. Acta Paulista de Enfermagem, São Paulo, v. 19, n. 2, p. 138-143, 2006.

MATOS, E.; PIRES, D. E. P. Práticas de cuidado na perspectiva interdisciplinar: um caminho promissor. Texto \& Contexto: Enfermagem, Florianópolis, v. 18, n. 2, p. 338-346, 2009.
MEZZOMO, J. C. Gestão da qualidade na saúde: princípios básicos. Barueri: Manole, 2001.

MINAYO, M. C. S. O desafio do conhecimento: pesquisa qualitativa em saúde. São Paulo: Hucitec, 2007.

PAIVA, S. A. R. et al. Análise de uma população de doentes atendidos em unidade de terapia intensiva. Revista Brasileira Terapia Intensiva, São Paulo, v. 14, n. 2, p. $73-$ 80, 2002.

PALM, R. D. C. M. Terapia Ocupacional em contextos hospitalários. TOG (A Corunã), Coruña, v. 13, n. 23, p. 1-10, 2016.

PASSOS, S. S. S. et al. O acolhimento no cuidado à família numa unidade de terapia intensiva. Revista Enfermagem UERJ, Rio de Janeiro, v. 23, n. 3, p. 368-374, 2015.

PETTENGILL, M. A. M.; ANGELO, M. Vulnerabilidade da família: desenvolvimento do conceito. Revista Latino-Americana de Enfermagem, Ribeirão Preto, v. 13, n. 6, p. 982-988, 2005. http://dx.doi.org/10.1590/ S0104-11692005000600010.

PROENÇA, M. O.; AGNOLO, C. M. D. Internação em unidade de terapia intensiva: percepção de pacientes. Revista Gaúcha de Enfermagem, Porto Alegre, v. 32, n. 2, p. 279-286, 2011.

SANTOS, C. A. V.; DE CARLO, M. M. R P. Hospital como campo de práticas: revisáo integrativa da literatura e a terapia ocupacional. Cadernos de Terapia Ocupacional da UFSCar, São Carlos, v. 21, n. 1, p. 99-107, 2013.

SCHMITT, R.; GOMES, R. H. Aspectos da interconsulta psiquiátrica em hospital de trauma. Revista de Psiquiatria do Rio Grande do Sul, Porto Alegre, v. 27, n. 1, p. 71-81, 2005.

\section{Contribuição dos Autores}

Tatiana Barbieri Bombarda: foi responsável pela revisão do material, concepção do artigo, organização de fontes e análise. Ana Luiza Lanza: foi responsável pela concepção do artigo e análise. Regina Helena Vitale Torkomian Joaquim e Claudia Aline Valente Santos: foram responsáveis pela análise e revisão do material. Todos os autores aprovaram a versão final do texto.

\section{Notas}

${ }^{1}$ Trata-se de um relato de experiência elaborado a partir da ciência e do consentimento da diretoria clínica do hospital, sendo respeitados os aspectos éticos nesta construção.

${ }^{2}$ A escala de Katz consiste em um instrumento de avaliaçáo do nível de independência nas atividades de vida diária (LINO et al., 2008). 